OPEN ACCESS

Edited by:

Jaewon Ko,

Daegu Gyeongbuk Institute of Science and Technology (DGIST),

South Korea

Reviewed by:

Monica Diluca,

University of Milan, Italy

Sajikumar Sreedharan,

National University of Singapore,

Singapore

*Correspondence: Nashaat Z. Gerges ngerges@mcw.edu

Received: 10 September 2019 Accepted: 17 December 2019 Published: 24 January 2020

Citation:

Zhong L and Gerges NZ (2020) Neurogranin Regulates Metaplasticity.

Front. Mol. Neurosci. 12:322. doi: 10.3389/fnmol.2019.00322

\section{Neurogranin Regulates Metaplasticity}

\author{
Ling Zhong and Nashaat Z. Gerges*
}

Department of Cell Biology, Neurobiology, and Anatomy, Medical College of Wisconsin, Milwaukee, WI, United States

Long-term potentiation (LTP) and long-term depression (LTD) are two major forms of synaptic plasticity that are widely accepted as cellular mechanisms involved in learning and memory. Metaplasticity is a process whereby modifications in synaptic processes shift the threshold for subsequent plasticity. While metaplasticity has been functionally observed, its molecular basis is not well understood. Here, we report that neurogranin $(\mathrm{Ng})$ regulates metaplasticity by shifting the threshold toward potentiation, i.e., increasing $\mathrm{Ng}$ in hippocampal neurons lowers the threshold for LTP and augments the threshold for LTD. We also show that $\mathrm{Ng}$ does not change the ultrastructural localization of calmodulin (CaM)-dependent protein Kinase II (CaMKII) or calcineurin, critical enzymes for the induction of LTP and LTD, respectively. Interestingly, while CaMKII concentrates close to the plasma membrane, calcineurin concentrates away from the plasma membrane. These data, along with the previous observation showing $\mathrm{Ng}$ targets CaM closer to the plasma membrane, suggesting that shifting the localization of CaM within the dendritic spines and closer to the plasma membrane, where there is more CaMKII, may be favoring the activation of CaMKII vs. that of calcineurin. Thus, the regulation of CaM localization/targeting within dendritic spines by $\mathrm{Ng}$ may provide a mechanistic basis for the regulation of metaplasticity.

Keywords: LTP, LTD, synaptic plasticity, calmodulin, neurogranin, CaMKII

\section{INTRODUCTION}

Synaptic connections modify their strength and undergo continuous remodeling in response to neuronal activity. This process, known as synaptic plasticity, is widely thought as the cellular basis underlying learning and memory (Alkon and Nelson, 1990; Bliss and Collingridge, 1993; Chen and Tonegawa, 1997; Baudry, 1998; Elgersma and Silva, 1999; Kandel et al., 2000; Martin et al., 2000; Maren, 2001; Benfenati, 2007). Long-term potentiation (LTP) and long-term depression (LTD) are the two best-characterized forms of synaptic plasticity. At excitatory synapses in the CA1 area, both LTP and LTD share a common pathway for their induction and coexist in a tight balance (Lisman, 1989; Mizuno et al., 2001). They both require synaptic activation of postsynaptic $\mathrm{N}$-methyl-D-aspartate (NMDA) receptors (NMDAR). Activation of NMDARs elevates the intracellular $\mathrm{Ca}^{2+}$ concentration within a specific range. Two $\mathrm{Ca}^{2+} /$ calmodulin (CaM)-dependent enzymes are essential for the bidirectional balance between LTP and LTD. $\mathrm{Ca}^{2+} / \mathrm{CaM}$-dependent protein phosphatase calcineurin, which is activated at low $\mathrm{Ca}^{2+} / \mathrm{CaM}$ concentration, is required for LTD (Klee et al., 1979; Hubbard and Klee, 1987; Mulkey et al., 1994; Torii et al., 1995; Zeng et al., 2001; Yasuda et al., 2003). On the other hand, $\mathrm{Ca}^{2+} / \mathrm{CaM}$-dependent protein Kinase II (CaMKII), 
which is activated at high $\mathrm{Ca}^{2+} / \mathrm{CaM}$ concentration, is required for LTP (Miller and Kennedy, 1985; Meyer et al., 1992; Silva et al., 1992; Giese et al., 1998; Hudmon and Schulman, 2002; Lisman et al., 2002; Kennedy et al., 2005; Shifman et al., 2006; Shonesy et al., 2014). Thus, CaM availability plays a crucial role in setting the balance between LTP and LTD.

One of the most abundant postsynaptic proteins that bind to $\mathrm{CaM}$ is neurogranin $(\mathrm{Ng})$, which is a neuron-specific protein that is enriched in the hippocampus and cortex (Represa et al., 1990; Gerendasy et al., 1994a,b). Two independent loss-of-function studies of $\mathrm{Ng}$ in mice highlight the importance of $\mathrm{Ng}$ in synaptic plasticity (Pak et al., 2000; Krucker et al., 2002). In this study, we explored the role of $\mathrm{Ng}$ in setting up synaptic plasticity balance by increasing $\mathrm{Ng}$ within CA1 hippocampal neurons. We have also explored whether $\mathrm{Ng}$ influences the ultrastructural localization of CaMKII and calcineurin using immunoelectron microscopy. Using a combination of molecular biology, electrophysiology, and electron microscopy, we have found that $\mathrm{Ng}$ shifts the frequency-response curve to the left without affecting CaMKII or calcineurin localization within dendritic spines. Interestingly, we have found that unlike CaMKII, which concentrates closer to the plasma membrane, calcineurin concentrates away from the plasma membrane. Taken together with our previous study showing that $\mathrm{Ng}$ concentrates CaM close to the plasma membrane highlights the significant role of $\mathrm{Ng}$ in setting the synaptic plasticity balance through the localized targeting of CaM within dendritic spines.

\section{MATERIALS AND METHODS}

\section{Animals and Hippocampal Slice Preparation}

Young Sprague-Dawley rats (postnatal day 5 or 6) were purchased from Charles River Laboratories (Portage, MI, USA) and maintained on a $12 \mathrm{~h}$ light/dark cycle (lights off at 6:00 P.M.). Organotypic hippocampal slices were prepared as described previously (Gähwiler et al., 1997). All biosafety procedures and animal care protocols described here were approved by the Medical College of Wisconsin Institutional Animal Care and Use Committee and were performed in strict accordance with the Guidelines for Care and Use of Laboratory Animals of the National Institutes of Health.

\section{DNA Constructs and Expression}

$\mathrm{Ng}$ was cloned by PCR from a commercial rat brain cDNA (Clontech, Mountain View, CA, USA). GFP-Ng was made with pEGFP plasmid and re-cloned into pSinRep5 (Invitrogen, Grand Island, NY, USA) for virus preparation as described (Zhong et al., 2009). After 5-7 days in culture, GFP-Ng was delivered into the slices using the Sindbis virus expression system, which is a replication-deficient, low-toxicity and neuron-specific system (Malinow et al., 1999).

\section{Post-embedding Immunogold Electron Microscopy}

Organotypic hippocampal slices were fixed and processed for osmium-free post-embedding immunogold labeling as described earlier (Phend et al., 1995). Briefly, the CA1 region was carefully removed from the hippocampal slice and fixed with $0.1 \%$ picric acid, $1 \%$ paraformaldehyde, and $2.5 \%$ glutaraldehyde in $0.1 \mathrm{M}$ phosphate buffer ( $\mathrm{pH} 7.3$ ) for $2 \mathrm{~h}$ at $4^{\circ} \mathrm{C}$. After fixation, tissues were washed in $0.1 \mathrm{M}$ maleate buffer $(\mathrm{pH}$ 6.0), treated with $1 \%$ tannic acid, $1 \%$ uranyl acetate, and $0.5 \%$ platinum chloride, followed by dehydration through a series of ethanol solutions. Tissues were then embedded in epoxy resins, sectioned and stained with $1 \%$ toluidine blue and $1 \%$ borax. CaMKII was labeled with an anti-CaMKII $\alpha$ antibody (a generous gift from Dr. Johannes Hell, University of California, Davis, Davis, CA, USA) and an anti-mouse antibody coupled to $15-\mathrm{nm}$ gold particles (Electron Microscopy Sciences, Hatfield, PA, USA). Calcineurin was labeled with an anti-calcineurin antibody (Sigma, St. Louis, MO, USA) and an anti-mouse antibody coupled to 10-nm gold particles (Electron Microscopy Sciences, Hatfield, PA, USA). Electron micrographs were obtained with a JOEL EM-2100 transmission electron microscope and an Orius SC 1000 CCD camera (JOEL, Peabody, MA, USA).

\section{Electrophysiology}

Synaptic responses in organotypic slice cultures were evoked with two bipolar electrodes (FHC, Bowdoin, ME, USA) placed on the Schaffer collateral fibers between 300 and $500 \mu \mathrm{m}$ of the recorded cells. The recording chamber was perfused with $119 \mathrm{mM} \mathrm{NaCl}$, $2.5 \mathrm{mM} \mathrm{KCl}, 4 \mathrm{mM} \mathrm{CaCl}, 4 \mathrm{mM} \mathrm{MgCl}_{2}, 26 \mathrm{mM} \mathrm{NaHCO}_{3}$, $1 \mathrm{mM} \mathrm{NaH} \mathrm{PO}_{4}, 11 \mathrm{mM}$ glucose, $0.1 \mathrm{mM}$ picrotoxin and $2 \mu \mathrm{M}$ 2-chloroadenosine, at $\mathrm{pH} 7.4$, and gassed with $5 \%$ $\mathrm{CO}_{2}, 95 \% \mathrm{O}_{2}$. Patch recording pipettes (3-6 M $\Omega$ ) were filled with $115 \mathrm{mM}$ cesium methanesulfonate, $20 \mathrm{mM} \mathrm{CsCl}, 10 \mathrm{mM}$ HEPES, $2.5 \mathrm{mM} \mathrm{MgCl}_{2}, 4 \mathrm{mM} \mathrm{Na} \mathrm{NTP}_{2}$, $0.4 \mathrm{mM} \mathrm{Na} \mathrm{m}_{3} \mathrm{GTP}$, $10 \mathrm{mM}$ sodium phosphocreatine and $0.6 \mathrm{mM}$ EGTA, at $\mathrm{pH}$ 7.25. LTD was induced by pairing $1 \mathrm{~Hz}$ presynaptic stimulation (500 pulses) with $-40 \mathrm{mV}$ postsynaptic depolarization. Voltageclamp whole-cell recordings were acquired with a Multiclamp 700A amplifier (Axon Instruments, Union City, CA, USA).

\section{Statistical Analysis}

Comparison of normalized average steady-state AMPA receptormediated responses between control uninfected neurons and $\mathrm{Ng}$-infected neurons were carried out using unpaired $t$-tests. A comparison of cumulative distributions was carried out with the Kolmogorov-Smirnov test. Comparisons of the distribution of calcineurin or CaMKII between control and Ng-infected conditions were achieved using Chi-squared test. Values were considered significantly different if $p \leq 0.05$, and marked with an asterisk. Error bars represent standard error of the mean in all figures.

\section{RESULTS}

\section{Ng Lowers LTD Expression}

Despite the significant role of $\mathrm{Ng}$ in learning and memory, the relevance of having more $\mathrm{Ng}$ in neurons on LTD induction has never been evaluated. To evaluate the role of $\mathrm{Ng}$ in LTD expression, we expressed $\mathrm{Ng}$ in organotypic hippocampal cultures and used whole-cell recordings from 


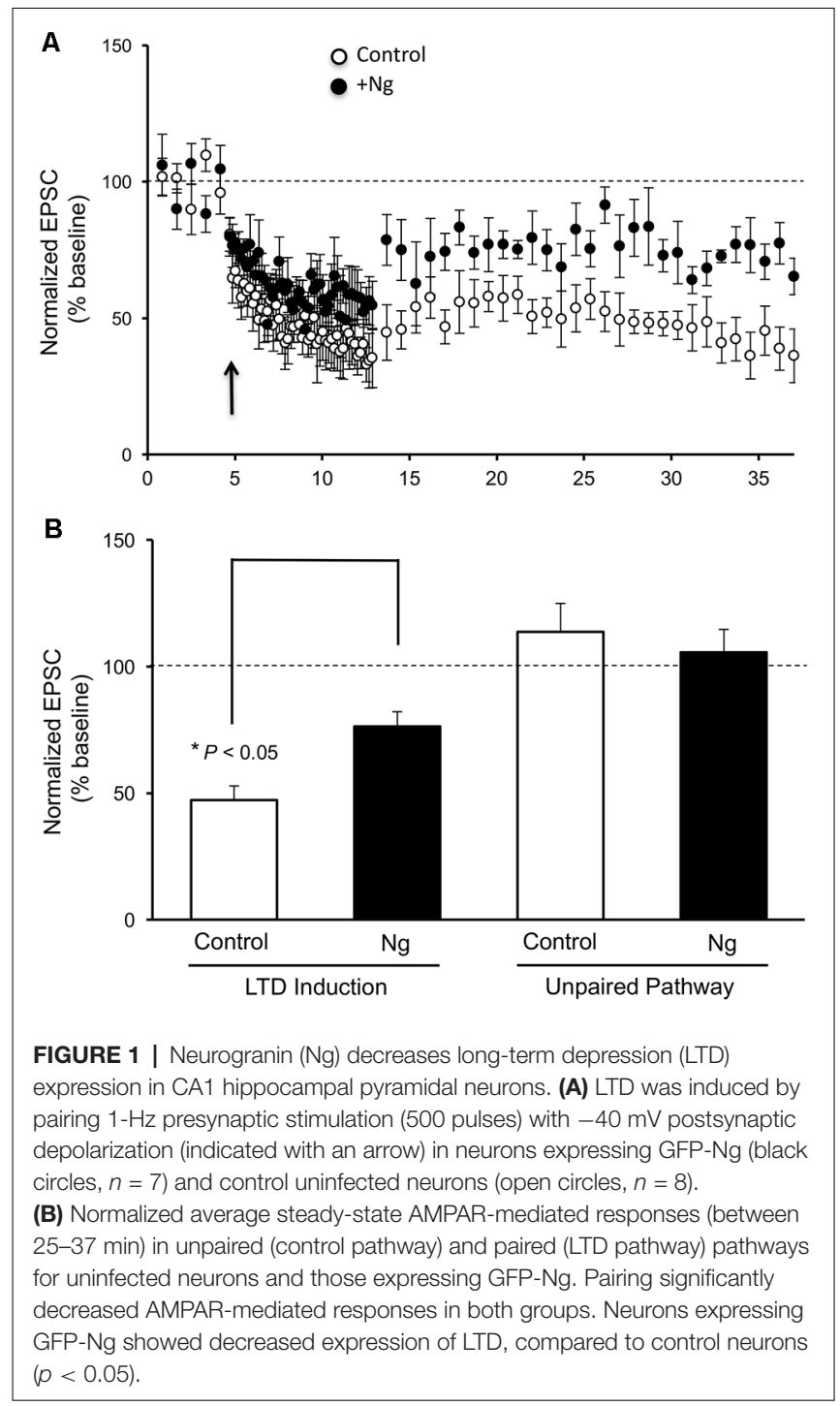

Ng-expressing and uninfected neurons under voltageclamp configuration. As shown in Figure 1, $\mathrm{Ng}$ expression significantly decreased LTD expression as compared to control neurons.

\section{Neurogranin Regulates Metaplasticity at CA1 Hippocampal Synapses}

Metaplasticity refers to the sensitivity to change the threshold of LTP and LTD. On a molecular level, only a few molecules have shown such an effect on the synaptic plasticity threshold between LTP and LTD, such as CaMKII and postsynaptic density (PSD)95. We wished to examine the role of $\mathrm{Ng}$ in metaplasticity regulation. We have previously shown that $\mathrm{Ng}$ facilitates LTP (Zhong and Gerges, 2010, 2012). In the current study, we show Ng depresses LTD (Figure 1). To this end, we have plotted the steady-state AMPAR-mediated responses from our two previously published protocols that we used to induce LTP (Zhong et al., 2009; Zhong and Gerges, 2012) along with the protocol that we used for the current study to induce LTD.

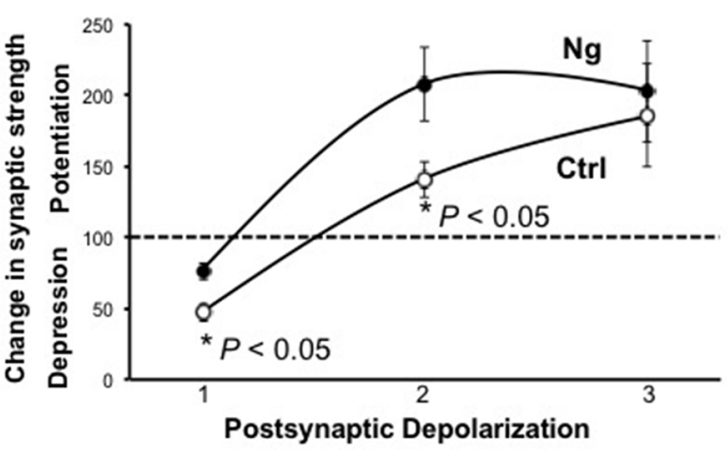

FIGURE 2 | Ng regulates metaplasticity at CA1 hippocampal synapses. The graph represents experimental data from control and $\mathrm{Ng}$-expressing neurons from organotypic hippocampal slices. All three protocols used were pairing protocols where presynaptic stimulation is paired with postsynaptic depolarization. Protocol \#1:1 Hz stimulation (500 pulses) paired with $-40 \mathrm{mV}$ depolarization. Protocol \#2:3 Hz stimulation (300 pulses) paired with $-20 \mathrm{mV}$ depolarization (Zhong and Gerges, 2012). The time-course of this experiment has been shown previously (Zhong and Gerges, 2012) Protocol \#3:3 Hz stimulation (300 pulses) paired with $0 \mathrm{mV}$ postsynaptic depolarization (Zhong et al., 2009). The time-course of this experiment has been shown previously (Zhong et al., 2009).

Figure 2 shows that $\mathrm{Ng}$ expression in CA1 hippocampal neurons results in a left shift. These data indicate that $\mathrm{Ng}$ regulates the metaplasticity at CA1 hippocampal neurons by favoring the induction of LTP and lowering that of LTD.

\section{$\mathrm{Ng}$ Does Not Change the Ultrastructural Localization of CaMKII}

We have previously shown that $\mathrm{Ng}$, CaM and CaMKII are not randomly distributed within dendritic spines and concentrate close to the plasma membrane (Zhong et al., 2009; Zhong and Gerges, 2012). Importantly, using post-embedding immunogold labeling electron microscopy, we have shown that increasing $\mathrm{Ng}$ levels targets more CaM close to the plasma membrane (Zhong and Gerges, 2012). Since Ng-mediated facilitation of synaptic plasticity is mediated by CaMKII, we wished to test the effect of increasing $\mathrm{Ng}$ on CaMKII distribution within the spine. To achieve this goal, we used post-embedding anti-CaMKII immunogold labeling on the synaptic region of the CA1 stratum radiatum of organotypic hippocampal slices overexpressing $\mathrm{Ng}$, as previously described (Kaleka et al., 2012). To quantitatively assess the ultrastructural localization of CaMKII postsynaptically, we analyzed the distribution in a way similar to the one described previously (Zhong et al., 2009; Zhong and Gerges, 2012). Briefly, to assess the radial distribution, the shortest distance of each gold particle to the plasma membrane was measured and then normalized to the radius of the spine. Quantitative examination of CaMKII distribution shows that $\mathrm{Ng}$ overexpression did not change the radial distribution of CaMKII within dendritic spines (Figures 3A,B). Thus, while the overexpression of $\mathrm{Ng}$ targets more CaM close to the plasma membrane (Zhong and Gerges, 2012), it does not change CaMKII distribution. 


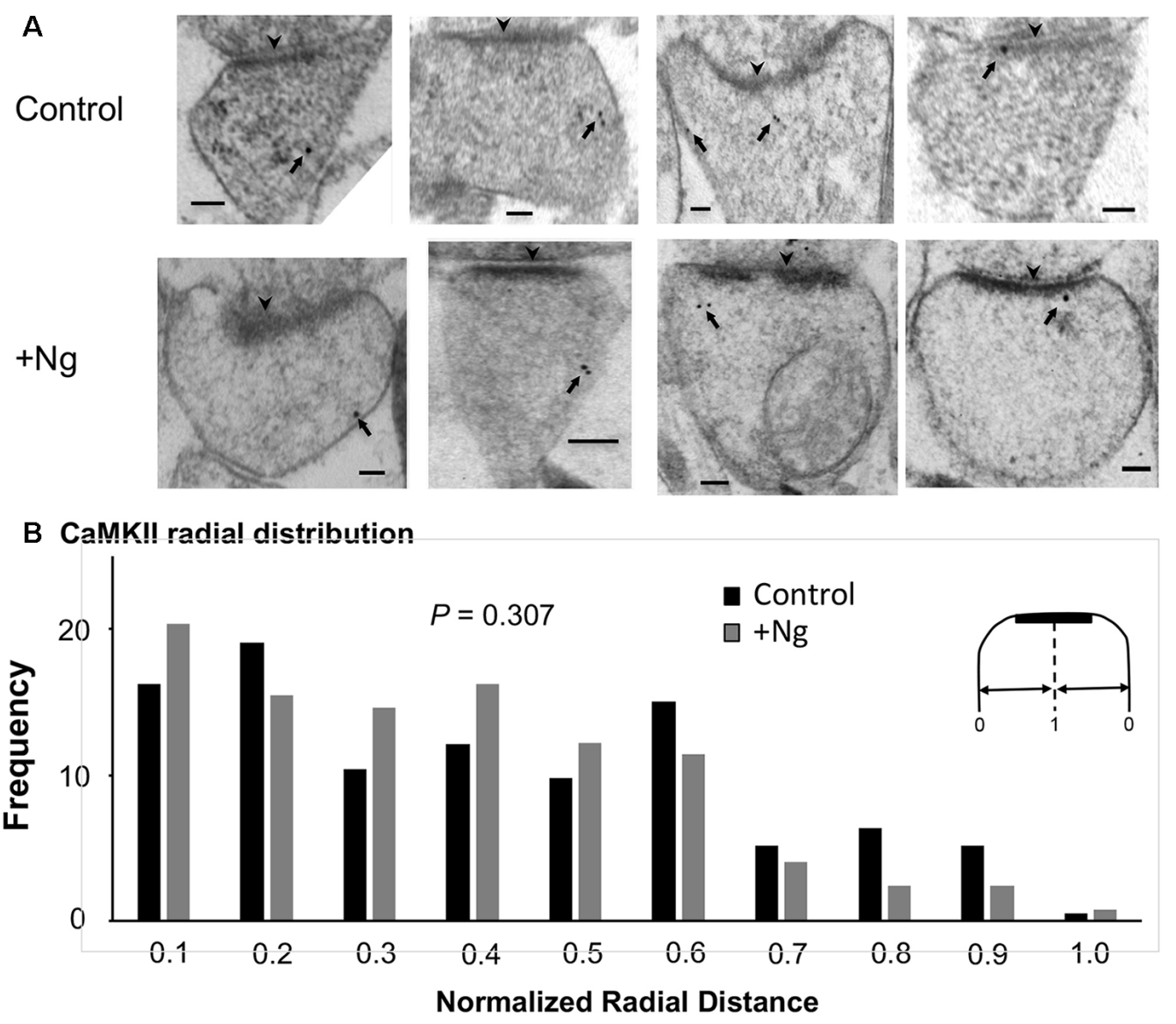

FIGURE 3 | Ng does not change the ultrastructural localization of calmodulin (CaM)-dependent protein Kinase II (CaMKII). (A) Representative micrographs of immunogold-EM for endogenous CaMKII in dendritic spines of the CA1 area for control and Ng-overexpressing neurons. The black arrowheads point to the postsynaptic density (PSD). Arrows indicate anti-CaMKII immunogold particles. Scale bar, $100 \mathrm{~nm}$. (B) Frequency histogram in control $(n=192)$ and Ng-overexpressing $(n=131)$ neurons. The distance of each gold particle was normalized (x-axis) to the corresponding radius of the spine measured through that particle. Ng does not change CaMKII radial distribution.

\section{Ng Does Not Change the Ultrastructural Localization of Calcineurin}

As mentioned above, $\mathrm{Ca}^{2+} / \mathrm{CaM}$-dependent enzymes are essential for the bidirectional balance between LTP and LTD. While CaMKII is required for LTP, calcineurin is required for LTD. Since changing the ultrastructural localization of calcineurin could result in a change in the probability of its activation, we wished to test whether the overexpression of $\mathrm{Ng}$ changes the ultrastructural localization of calcineurin. To test this possibility, we first wished to understand the precise ultrastructural localization of endogenous calcineurin within dendritic spines. As shown in Figures 4A,B, calcineurin distribution is not random within dendritic spines. Interestingly, the highest frequency of calcineurin labeling was not found close to the plasma membrane (Figure 4C).

To investigate whether $\mathrm{Ng}$ influences calcineurin localization, we performed similar immunogold-EM labeling for calcineurin in tissues overexpressing $\mathrm{Ng}$. $\mathrm{Ng}$ did not change the ultrastructural localization of calcineurin (Figure 5).

\section{Radial Distribution of Endogenous Ng, CaM, CaMKII and Calcineurin}

While $\mathrm{Ng}$ did not change the ultrastructural localization of CaMKII or calcineurin, $\mathrm{Ng}$ does target $\mathrm{CaM}$ close to the plasma membrane (Zhong and Gerges, 2012). A closer look at the radial distribution indicates that while $\mathrm{Ng}, \mathrm{CaM}$, and CaMKII have a similar radial distribution (i.e., the highest concentration close to the plasma membrane), calcineurin distribution is distinct. Figure $\mathbf{6}$ shows the heat maps for the radial distribution of endogenous Ng (Zhong et al., 2009), CaM (Zhong and Gerges, 2012), CaMKII and calcineurin. These data suggest that $\mathrm{Ng}$ targeting of CaM closer to the plasma membrane within dendritic spines favors the activation of CaMKII at the expense of calcineurin.

\section{DISCUSSION}

Neuronal activity changes synaptic transmission. Long-lasting changes in synaptic transmission/strength are widely thought of as the cellular mechanisms of learning and memory. LTP 
A

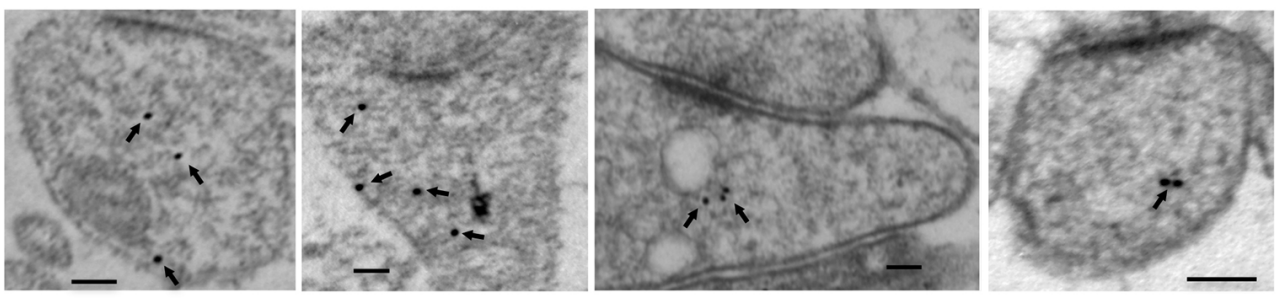

\section{CaN radial distribution}

- Random Distribution Calcineurin (CaN)
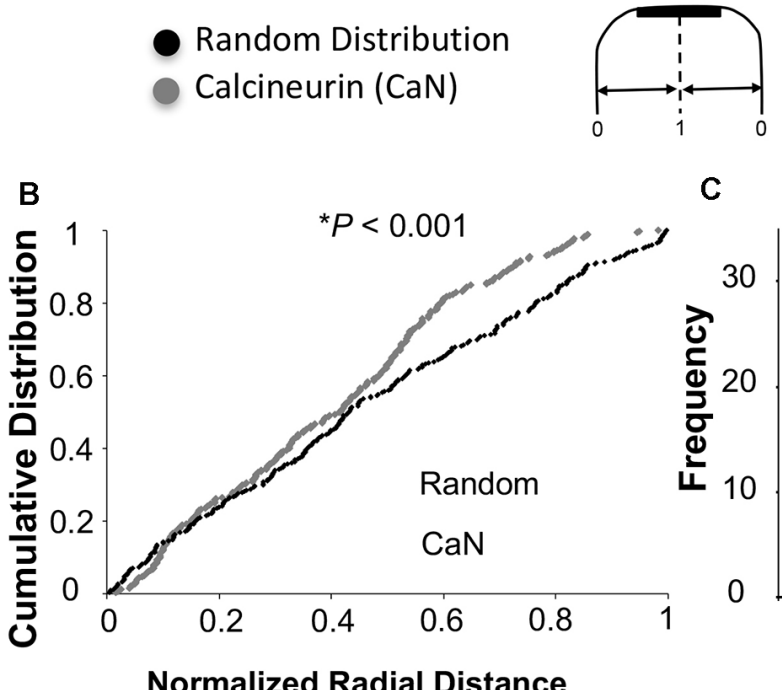

C

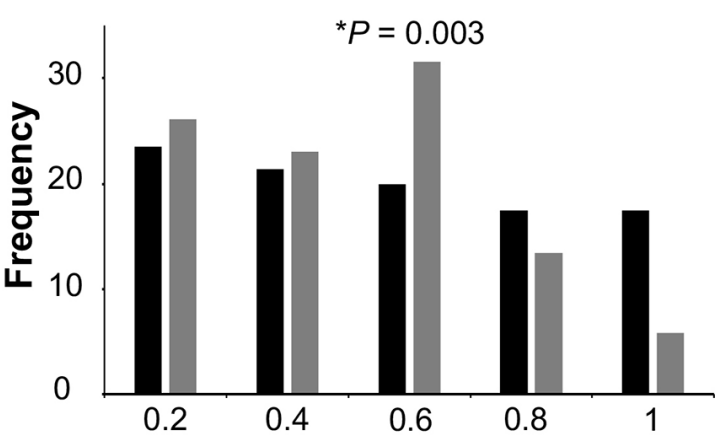

Normalized Radial Distance

FIGURE 4 | Ultrastructural localization of calcineurin. (A) Representative micrographs of immunogold-EM for calcineurin (CaN). (B) Cumulative probabilities of normalized radial distance. Normalized radial distribution was measured in the same way as described in Figure $\mathbf{3}$. The distribution of calcineurin within the spine $(n=291)$ is significantly different from a theoretical random distribution (Kolmogorov-Smirnov test, $p<0.001)$. (C) Frequency histogram for the data presented in (B) also showing that calcineurin distribution is significantly different from a theoretical random distribution using Chi-square. Interestingly, the highest fraction of labeling for calcineurin is not close to the plasma membrane but rather closer to the center of the spine (0.6 of the radial distance).

and LTD are the most-studied forms of synaptic plasticity. Metaplasticity, a term that was coined by Abraham and Bear (Abraham and Bear, 1996), refers to the sensitivity to change the threshold of LTP and LTD. Both LTP and LTD induction depends on the NMDAR-mediated Calcium rise within dendritic spines and the subsequent activation of $\mathrm{Ca} / \mathrm{CaM}$-dependent enzymes. Thus the threshold of potentiation/depression (and hence metaplasticity) is dependent on the decision of CaM to either activate CaMKII (and hence the induction of LTP) or to activate calcineurin (and hence the induction of LTD). In this study, we show that $\mathrm{Ng}$, a CaM-binding protein, regulates metaplasticity at CA1 hippocampal neurons.

It has been postulated that the differential affinity of $\mathrm{CaM}$ CaMKII and calcineurin is the sole determinant of $\mathrm{CaM}$ fate whether to activate CaMKII or calcineurin and subsequently induce LTP or LTD, respectively. The current study investigates the possible importance of the relative ultrastructural localization of $\mathrm{Ng}$, CaM, CaMKII and calcineurin as a factor in regulating metaplasticity. While increased $\mathrm{Ng}$ expression does not change the ultrastructural localization of CaMKII or calcineurin, we have shown previously that $\mathrm{Ng}$ does target more $\mathrm{CaM}$ close to the plasma membrane within dendritic spines (Zhong and Gerges, 2012). In this study, calcineurin distribution reveals that the highest concentration of calcineurin does not lie closer to the plasma membrane, unlike $\mathrm{Ng}$, $\mathrm{CaM}$ or CaMKII. Thus the ability of $\mathrm{Ng}$ to target more $\mathrm{CaM}$ close to the plasma membrane (where there is more CaMKII) may facilitate its activation and therefore, may facilitate LTP at the expense of LTD (i.e., produce a left-shift in the frequency-response curve).

Two independent loss-of-function studies of $\mathrm{Ng}$ in mice highlight the important function of $\mathrm{Ng}$ in regulating synaptic plasticity (Pak et al., 2000; Krucker et al., 2002; Huang et al., 2004). However, these studies gave opposite results, most likely due to the methodology employed for knocking out Ng. Interestingly, the study that had a complete knockout of $\mathrm{Ng}$ (Huang et al., 2004) showed a right shift of frequencyresponse curve, complementing our data here showing that increasing $\mathrm{Ng}$ results in a left shift of the frequency-response 

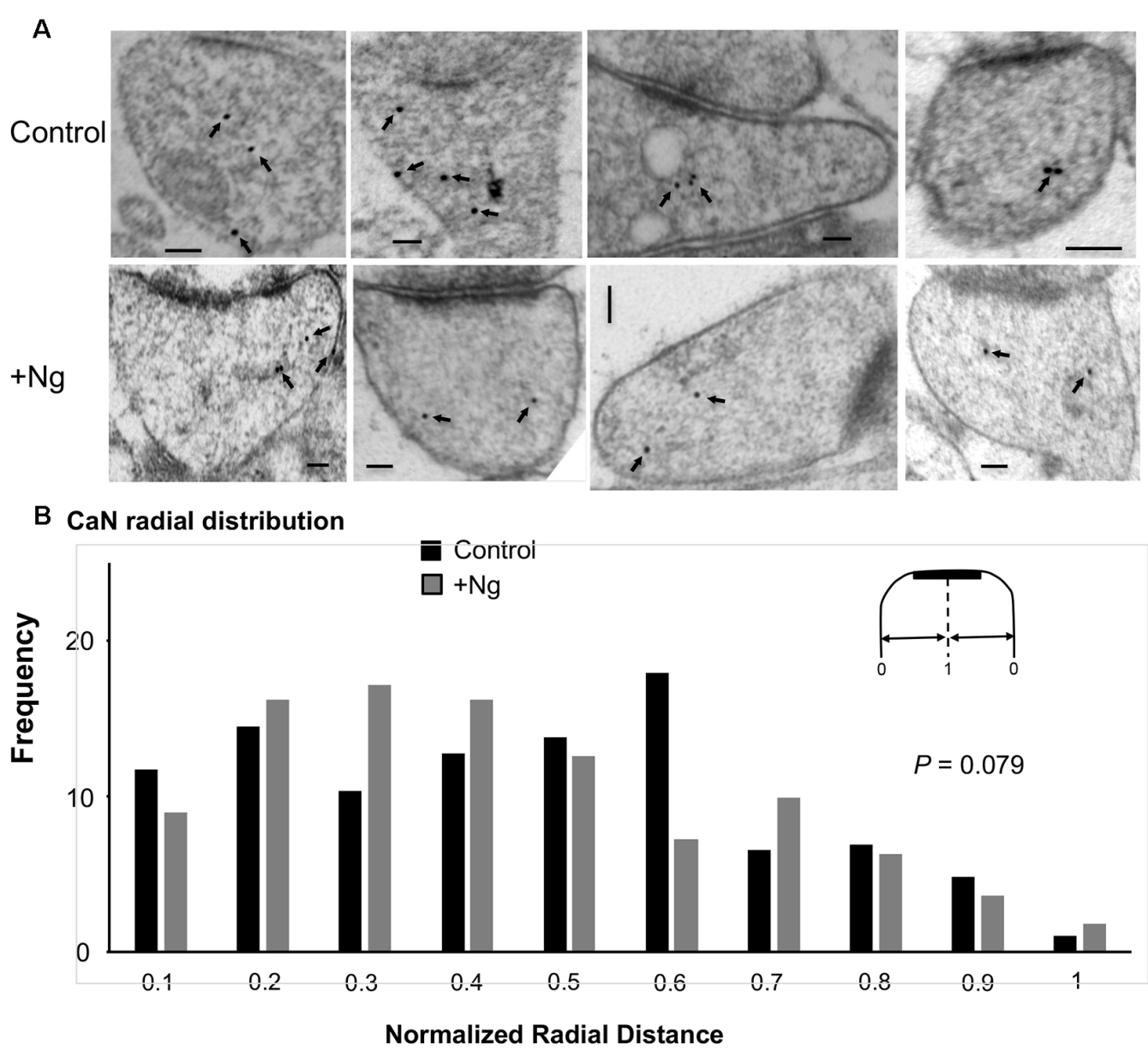

FIGURE 5 | Ng does not change the ultrastructural localization of calcineurin. (A) Representative micrographs of immunogold-EM for calcineurin in control (same as of Figure 4) and Ng-overexpressing neurons. Scale bar, $100 \mathrm{~nm}$. (B) Frequency histogram of the normalized radial distance of calcineurin particles. Ng does not change calcineurin radial distribution.

curve (i.e., increasing $\mathrm{Ng}$ favors LTP at the expense of LTD). Our findings are also in agreement with a computational study showing the need for a higher $\mathrm{Ng}$ concentration in the spines to be able to induce LTP at the expense of LTD (Zhabotinsky et al., 2006). Furthermore, a recent study showed that the downregulation of $\mathrm{Ng}$ lowered the threshold of LTD expression (Han et al., 2017). It remains to be tested, however, whether $\mathrm{Ng}$ can affect subsequent plasticity induction.

While there is a long list of molecules (Sanes and Lichtman, 1999) that block LTP induction, it is hard to believe that all of the molecules in this list control the synaptic plasticity balance. In fact, only a few manipulations have been described to influence the balance between LTP and LTD. For example, stress shifts the balance to the right, i.e., toward depression (Kim and Yoon, 1998). On the other hand, neurogenesis produces a left shift, i.e., toward potentiation (Garcia, 2002). Pharmacologically, prior NMDAR activation has been found to produce a right shift (Mockett et al., 2002). Conversely, prior activation of metabotropic glutamate receptors produced a left shift (Rush et al., 2002).
On a molecular level, only a few molecules have shown such an effect on the synaptic plasticity threshold between LTP and LTD. For example, overexpression of PSD95 occludes LTP and enhances LTD (Stein et al., 2003; Ehrlich and Malinow, 2004). Similarly, expression of the constitutively active form of CaMKII occludes LTP and favors the expression of LTD (Mayford et al., 1995). It is important to highlight that the effects of $\mathrm{Ng}$, unlike the constitutively active CaMKII, are dependent on activity and the activation of NMDAR. Thus while the expression of the constitutively active CaMKII impairs learning and memory, $\mathrm{Ng}$ expression is expected to enhance learning and memory. This is indeed the case with transgenic mice overexpressing $\mathrm{Ng}$ in the prefrontal cortex (Zhong et al., 2015). For example, these mice exhibit higher extinction learning, a task that is dependent on PFC plasticity. The significant role of Ng in enhancing learning and memory was further supported by a recent study showing that the upregulation of $\mathrm{Ng}$ enables durable context encoding (Jones et al., 2018).

Either the inability of hippocampal neurons to express LTD (Mills et al., 2014) or the enhanced expression of LTD 

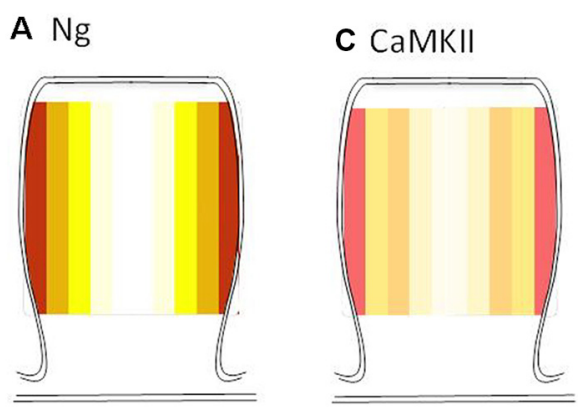

B CaM

D CaN

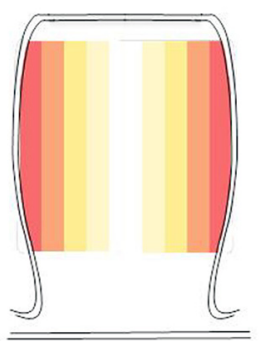

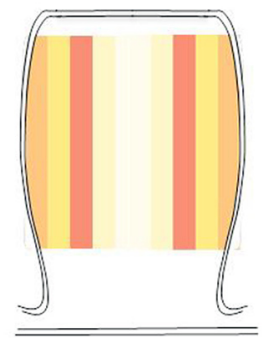

FIGURE 6 | Radial distribution of endogenous Ng, CaM, CaMKIII, and calcineurin. Heat maps were generated based on the actual radial distribution of endogenous $\mathrm{Ng}$ (A), CaM (B), CaMKII (C) and calcineurin (D) from immuno-EM labeling. Note that while CaMKII, CaM, and $\mathrm{Ng}$ have their highest concentration close to the plasma membrane, calcineurin has its highest concentration away from the plasma membrane of the dendritic spines. Note: $\mathrm{Ng}$ and $\mathrm{CaM}$ heat maps were generated by re-analyzing immunoEM data from Zhong et al. (2009) and Zhong and Gerges (2012), respectively.

(Nosyreva and Huber, 2006) is often associated with cognitive deficits. However, manipulations that result in a left shift in the frequency-response curve (i.e., reduction in LTD expression) may be beneficial to memory. For example, prior activation of metabotropic glutamate receptors is associated with reduced LTD and enhanced memory (Rudy and Matus-Amat, 2009). We have recently shown that overexpression of $\mathrm{Ng}$ also enhances memory (Zhong et al., 2015). It remains to be tested, however, whether the enhanced memory as a result of increased $\mathrm{Ng}$ is due to the facilitation of LTP per se, the reduction of LTD per se, or the shift in the synaptic plasticity balance (i.e., the regulation of metaplasticity).

Our data support a model in which $\mathrm{Ng}$ regulates metaplasticity by shifting the frequency-response curve of synaptic plasticity curve to the left (i.e., facilitating LTP and lowering LTD; Figure 7). While $\mathrm{Ng}$ does not change the ultrastructural localization of CaMKII or calcineurin, $\mathrm{Ng}$ concentrates more CaM close to the plasma membrane of dendritic spines. Since CaMKII concentrates closer to the plasma membrane more than calcineurin does, Ng-mediated increases in CaM close to the plasma membrane may preferentially favor the potential activation of CaMKII over calcineurin. It is important to note that we have previously shown that $\mathrm{Ng}$ overexpression does not change NMDAR-mediated responses (Zhong et al., 2009), supporting a regulatory role of $\mathrm{Ng}$ in

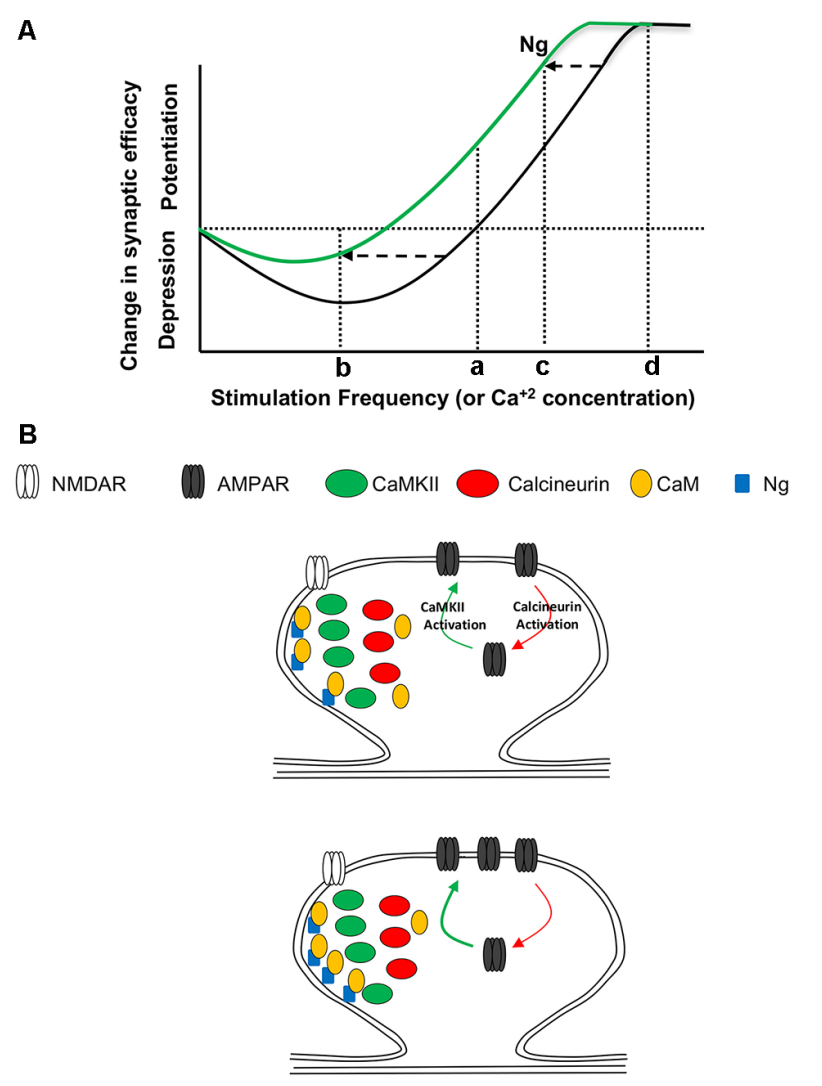

FIGURE 7 | Ng and Metaplasticity. (A) Schematic diagram representing the changes in synaptic plasticity strength in response to various stimulation frequencies. Under normal conditions (black line), low-frequency stimulation (b) results in depression, while high-frequency stimulation (c) results in potentiation. Only a few things have been found to slide the whole curve; see "Discussion" section for details. This metaplasticity is similar to that described by the "sliding threshold" feature of the Bienenstock, Cooper and Munro model (BCM theory) of experience-dependent synaptic plasticity. This theoretical diagram resembles Figure 2 . The various postsynaptic depolarization protocols used, represented by 1,2 and 3 in Figure 2, are schematically equivalent to the stimulation frequencies $\mathrm{b}, \mathrm{c}$, and $\mathrm{d}$, respectively. (B) A working model for $\mathrm{Ng}$ regulation of metaplasticity. (Top) While CaMKII, similar to $\mathrm{Ng}$, concentrates closer to the plasma membrane, calcineurin concentrates away from the plasma membrane. Both CaMKII and calcineurin require $\mathrm{Ca}^{2+}$ and $\mathrm{CaM}$ to be activated. The activation of CaMKII results in the insertion of AMPA receptors and thus the expression of long-term potentiation (LTP). On the other hand, the activation of calcineurin results in the removal of AMPA receptors and thus the expression of LTD. (Bottom) Increasing $\mathrm{Ng}$ does not change the ultrastructural localization of CaMKII or calcineurin. Nonetheless, increasing Ng targets more CaM closer to the plasma membrane, where there is more CaMKII; thus increasing the chance of CaMKII activation, while decreasing the chance of CaN activation. This may explain, at least partly, why Ng shifts the synaptic plasticity curve to the left (i.e., regulating metaplasticity).

targeting CaM, rather than a global influencer role on the various signaling cascade.

\section{DATA AVAILABILITY STATEMENT}

The datasets generated for this study are available on request to the corresponding author. 


\section{ETHICS STATEMENT}

The animal study was reviewed and approved by the Medical College of Wisconsin Institutional Animal Care and Use Committee and were performed in strict accordance with the Guidelines for Care and Use of Laboratory Animals of the National Institutes of Health.

\section{AUTHOR CONTRIBUTIONS}

LZ and NG designed and performed the experiments, analyzed the data and wrote the manuscript.

\section{REFERENCES}

Abraham, W. C., and Bear, M. F. (1996). Metaplasticity: the plasticity of synaptic plasticity. Trends Neurosci. 19, 126-130. doi: 10.1016/s0166-2236(96)80018-x

Alkon, D. L., and Nelson, T. J. (1990). Specificity of molecular changes in neurons involved in memory storage. FASEB J. 4, 1567-1576. doi: 10.1096/fasebj.4.6. 2108074

Baudry, M. (1998). Synaptic plasticity and learning and memory: 15 years of progress. Neurobiol. Learn. Mem. 70, 113-118. doi: 10.1006/nlme.1998.3842

Benfenati, F. (2007). Synaptic plasticity and the neurobiology of learning and memory. Acta Biomed. 78, 58-66.

Bliss, T. V., and Collingridge, G. L. (1993). A synaptic model of memory: long-term potentiation in the hippocampus. Nature 361,31-39. doi: 10.1038/361031a0

Chen, C., and Tonegawa, S. (1997). Molecular genetic analysis of synaptic plasticity, activity-dependent neural development, learning, and memory in the mammalian brain. Annu. Rev. Neurosci. 20, 157-184. doi: 10.1146/annurev. neuro.20.1.157

Ehrlich, I., and Malinow, R. (2004). Postsynaptic density 95 controls AMPA receptor incorporation during long-term potentiation and experience-driven synaptic plasticity. J. Neurosci. 24, 916-927. doi: 10.1523/jneurosci.4733-03. 2004

Elgersma, Y., and Silva, A. J. (1999). Molecular mechanisms of synaptic plasticity and memory. Curr. Opin. Neurobiol. 9, 209-213. doi: 10.1016/s09594388(99)80029-4

Gähwiler, B. H., Capogna, M., Debanne, D., McKinney, R. A., and Thompson, S. M. (1997). Organotypic slice cultures: a technique has come of age. Trends Neurosci. 20, 471-477. doi: 10.1016/s0166-2236(97)01122-3

Garcia, R. (2002). Stress, metaplasticity, and antidepressants. Curr. Mol. Med. 2, 629-638. doi: 10.2174/1566524023362023

Gerendasy, D. D., Herron, S. R., Watson, J. B., and Sutcliffe, J. G. (1994a). Mutational and biophysical studies suggest RC3/neurogranin regulates calmodulin availability. J. Biol. Chem. 269, 22420-22426.

Gerendasy, D. D., Herron, S. R., Wong, K. K., Watson, J. B., and Sutcliffe, J. G. (1994b). Rapid purification, site-directed mutagenesis, and initial characterization of recombinant RC3/neurogranin. J. Mol. Neurosci. 5, 133-148. doi: 10.1007/bf02736729

Giese, K. P., Fedorov, N. B., Filipkowski, R. K., and Silva, A. J. (1998). Autophosphorylation at Thr286 of the alpha calcium-calmodulin kinase II in LTP and learning. Science 279, 870-873. doi: 10.1126/science.279.5352.870

Han, K. S., Cooke, S. F., and Xu, W. (2017). Experience-dependent equilibration of AMPAR-mediated synaptic transmission during the critical period. Cell Rep. 18, 892-904. doi: 10.1016/j.celrep.2016.12.084

Huang, K. P., Huang, F. L., Jager, T., Li, J., Reymann, K. G., and Balschun, D. (2004). Neurogranin/RC3 enhances long-term potentiation and learning by promoting calcium-mediated signaling. J. Neurosci. 24, 10660-10669. doi: 10.1523/jneurosci.2213-04.2004

Hubbard, M. J., and Klee, C. B. (1987). Calmodulin binding by calcineurin. Ligandinduced renaturation of protein immobilized on nitrocellulose. J. Biol. Chem. $262,15062-15070$.

Hudmon, A., and Schulman, H. (2002). Neuronal CA2+/calmodulin-dependent protein kinase II: the role of structure and autoregulation in cellular function.

\section{FUNDING}

This work was supported by grants from Advancing a Healthier Wisconsin and Alzheimer's Association to NG. This work was also supported by the Research and Education Initiative Fund, a component of the Advancing a Healthier Wisconsin Endowment at the Medical College of Wisconsin.

\section{ACKNOWLEDGMENTS}

We thank Matthew Florence and Clive Wells for excellent technical assistance. We thank Christopher Olsen for critical discussions of the data and review of the manuscript.

Annu. Rev. Biochem. 71, 473-510. doi: 10.1146/annurev.biochem.71.110601. 135410

Jones, K. J., Templet, S., Zemoura, K., Kuzniewska, B., Pena, F. X., Hwang, H., et al. (2018). Rapid, experience-dependent translation of neurogranin enables memory encoding. Proc. Natl. Acad. Sci. U S A 115, E5805-E5814. doi: 10.1073/pnas.1716750115

Kaleka, K. S., Petersen, A. N., Florence, M. A., and Gerges, N. Z. (2012). Pull-down of calmodulin-binding proteins. J. Vis. Exp. 59:3502. doi: 10.3791/3502

Kandel, E. R., Schwartz, J. H., and Jessell, T. M. (2000). Principles of Neural Science. 4th edn. New York, NY: McGraw-Hill.

Kennedy, M. B., Beale, H. C., Carlisle, H. J., and Washburn, L. R. (2005). Integration of biochemical signalling in spines. Nat. Rev. Neurosci. 6, 423-434. doi: $10.1038 / \mathrm{nrn} 1685$

Kim, J. J., and Yoon, K. S. (1998). Stress: metaplastic effects in the hippocampus. Trends Neurosci. 21, 505-509. doi: 10.1016/s0166-2236(98)01322-8

Klee, C. B., Crouch, T. H., and Krinks, M. H. (1979). Calcineurin: a calcium- and calmodulin-binding protein of the nervous system. Proc. Natl. Acad. Sci. U S A 76, 6270-6273. doi: 10.1073/pnas.76.12.6270

Krucker, T., Siggins, G. R., McNamara, R. K., Lindsley, K. A., Dao, A., Allison, D. W., et al. (2002). Targeted disruption of RC3 reveals a calmodulinbased mechanism for regulating metaplasticity in the hippocampus. J. Neurosci. 22, 5525-5535. doi: 10.1523/jneurosci.22-13-05525.2002

Lisman, J. (1989). A mechanism for the Hebb and the anti-Hebb processes underlying learning and memory. Proc. Natl. Acad. Sci. U S A 86, 9574-9578. doi: $10.1073 /$ pnas.86.23.9574

Lisman, J., Schulman, H., and Cline, H. (2002). The molecular basis of CaMKII function in synaptic and behavioural memory. Nat. Rev. Neurosci. 3, 175-190. doi: $10.1038 /$ nrn753

Malinow, R., Hayashi, Y., Maletic-Savatic, M., Zaman, S., Poncer, J.-C., Shi, S.-H., et al. (1999). "Introduction of green fluorescent protein into hippocampal neurons through viral infection," in Imaging Neurons, eds R. Yuste, F. Lanni and A. Konnerth (New York, NY: Cold Spring Harbor Press), 51-58.

Maren, S. (2001). Neurobiology of Pavlovian fear conditioning. Annu. Rev. Neurosci. 24, 897-931. doi: 10.1146/annurev.neuro.24.1.897

Martin, S. J., Grimwood, P. D., and Morris, R. G. (2000). Synaptic plasticity and memory: an evaluation of the hypothesis. Annu. Rev. Neurosci. 23, 649-711. doi: 10.1146/annurev.neuro.23.1.649

Mayford, M., Wang, J., Kandel, E. R., and O’Dell, T. J. (1995). CaMKII regulates the frequency-response function of hippocampal synapses for the production of both LTD and LTP. Cell 81, 891-904. doi: 10.1016/0092-8674(95) 90009-8

Meyer, T., Hanson, P. I., Stryer, L., and Schulman, H. (1992). Calmodulin trapping by calcium-calmodulin-dependent protein kinase. Science 256, 1199-1202. doi: 10.1126/science.256.5060.1199

Miller, S. G., and Kennedy, M. B. (1985). Distinct forebrain and cerebellar isozymes of type II $\mathrm{Ca}^{2}+/$ calmodulin-dependent protein kinase associate differently with the postsynaptic density fraction. J. Biol. Chem. 260, 9039-9046.

Mills, F., Bartlett, T. E., Dissing-Olesen, L., Wisniewska, M. B., Kuznicki, J., Macvicar, B. A., et al. (2014). Cognitive flexibility and long-term depression 
(LTD) are impaired following $\beta$-catenin stabilization in vivo. Proc. Natl. Acad. Sci. U S A 111, 8631-8636. doi: 10.1073/pnas.1404670111

Mizuno, T., Kanazawa, I., and Sakurai, M. (2001). Differential induction of LTP and LTD is not determined solely by instantaneous calcium concentration: an essential involvement of a temporal factor. Eur. J. Neurosci. 14, 701-708. doi: 10.1046/j.0953-816x.2001.01679.x

Mockett, B., Coussens, C., and Abraham, W. C. (2002). NMDA receptor-mediated metaplasticity during the induction of long-term depression by low-frequency stimulation. Eur. J. Neurosci. 15, 1819-1826. doi: 10.1046/j.1460-9568.2002. 02008.x

Mulkey, R. M., Endo, S., Shenolikar, S., and Malenka, R. C. (1994). Involvement of a calcineurin/inhibitor-1 phosphatase cascade in hippocampal long-term depression. Nature 369, 486-488. doi: 10.1038/369486a0

Nosyreva, E. D., and Huber, K. M. (2006). Metabotropic receptor-dependent long-term depression persists in the absence of protein synthesis in the mouse model of fragile X syndrome. J. Neurophysiol. 95, 3291-3295. doi: 10.1152/jn. 01316.2005

Pak, J. H., Huang, F. L., Li, J., Balschun, D., Reymann, K. G., Chiang, C., et al. (2000). Involvement of neurogranin in the modulation of calcium/calmodulindependent protein kinase II, synaptic plasticity, and spatial learning: a study with knockout mice. Proc. Natl. Acad. Sci. U S A 97, 11232-11237. doi: 10.1073/pnas.210184697

Phend, K. D., Rustioni, A., and Weinberg, R. J. (1995). An osmium-free method of epon embedment that preserves both ultrastructure and antigenicity for post-embedding immunocytochemistry. J. Histochem. Cytochem. 43, 283-292. doi: $10.1177 / 43.3 .7532656$

Represa, A., Deloulme, J. C., Sensenbrenner, M., Ben-Ari, Y., and Baudier, J. (1990). Neurogranin: immunocytochemical localization of a brain-specific protein kinase C substrate. J. Neurosci. 10, 3782-3792. doi: 10.1523/jneurosci. 10-12-03782.1990

Rudy, J. W., and Matus-Amat, P. (2009). DHPG activation of group 1 mGluRs in BLA enhances fear conditioning. Learn. Mem. 16, 421-425. doi: 10.1101/lm. 1444909

Rush, A. M., Wu, J., Rowan, M. J., and Anwyl, R. (2002). Group I metabotropic glutamate receptor (mGluR)-dependent long-term depression mediated via p38 mitogen-activated protein kinase is inhibited by previous high-frequency stimulation and activation of mGluRs and protein kinase $\mathrm{C}$ in the rat dentate gyrus in vitro. J. Neurosci. 22, 6121-6128. doi: 10.1523/jneurosci.22-14-061 21.2002

Sanes, J. R., and Lichtman, J. W. (1999). Can molecules explain long-term potentiation? Nat. Neurosci. 2, 597-604. doi: 10.1038/10154

Shifman, J. M., Choi, M. H., Mihalas, S., Mayo, S. L., and Kennedy, M. B. (2006). Ca2+/calmodulin-dependent protein kinase II (CaMKII) is activated by calmodulin with two bound calciums. Proc. Natl. Acad. Sci. U S A 103, 13968-13973. doi: 10.1073/pnas.0606433103

Shonesy, B. C., Jalan-Sakrikar, N., Cavener, V. S., and Colbran, R. J. (2014). CaMKII: a molecular substrate for synaptic plasticity and memory. Prog. Mol. Biol. Transl. Sci. 122, 61-87. doi: 10.1016/B978-0-12-420170-5.00003-9
Silva, A. J., Wang, Y., Paylor, R., Wehner, J. M., Stevens, C. F., and Tonegawa, S. (1992). Alpha calcium/calmodulin kinase II mutant mice: deficient long-term potentiation and impaired spatial learning. Cold Spring Harb. Symp. Quant. Biol. 57, 527-539. doi: 10.1101/sqb.1992.057.01.058

Stein, V., House, D. R., Bredt, D. S., and Nicoll, R. A. (2003). Postsynaptic density-95 mimics and occludes hippocampal long-term potentiation and enhances long-term depression. J. Neurosci. 23, 5503-5506. doi: 10.1523/jneurosci.23-13-05503.2003

Torii, N., Kamishita, T., Otsu, Y., and Tsumoto, T. (1995). An inhibitor for calcineurin, FK506, blocks induction of long-term depression in rat visual cortex. Neurosci. Lett. 185, 1-4. doi: 10.1016/0304-3940(94) 11210-a

Yasuda, H., Higashi, H., Kudo, Y., Inoue, T., Hata, Y., Mikoshiba, K., et al. (2003). Imaging of calcineurin activated by long-term depression-inducing synaptic inputs in living neurons of rat visual cortex. Eur. J. Neurosci. 17, 287-297. doi: 10.1046/j.1460-9568.2003.02449.x

Zeng, H., Chattarji, S., Barbarosie, M., Rondi-Reig, L., Philpot, B. D., Miyakawa, T., et al. (2001). Forebrain-specific calcineurin knockout selectively impairs bidirectional synaptic plasticity and working/episodic-like memory. Cell 107, 617-629. doi: 10.1016/s0092-8674(01)00585-2

Zhabotinsky, A. M., Camp, R. N., Epstein, I. R., and Lisman, J. E. (2006). Role of the neurogranin concentrated in spines in the induction of long-term potentiation. J. Neurosci. 26, 7337-7347. doi: 10.1523/jneurosci.0729-06.2006

Zhong, L., Brown, J., Kramer, A., Kaleka, K., Petersen, A., Krueger, J. N., et al. (2015). Increased prefrontal cortex neurogranin enhances plasticity and extinction learning. J. Neurosci. 35, 7503-7508. doi: 10.1523/jneurosci.027415.2015

Zhong, L., Cherry, T., Bies, C. E., Florence, M. A., and Gerges, N. Z. (2009). Neurogranin enhances synaptic strength through its interaction with calmodulin. EMBO J. 28, 3027-3039. doi: 10.1038/emboj. 2009.236

Zhong, L., and Gerges, N. Z. (2010). Neurogranin and synaptic plasticity balance. Commun. Integr. Biol. 3, 340-342. doi: 10.4161/cib.3.4.11763

Zhong, L., and Gerges, N. Z. (2012). Neurogranin targets calmodulin and lowers the threshold for the induction of long-term potentiation. PLoS One 7:e41275. doi: 10.1371/journal.pone.0041275

Conflict of Interest: The authors declare that the research was conducted in the absence of any commercial or financial relationships that could be construed as a potential conflict of interest.

Copyright $\odot 2020$ Zhong and Gerges. This is an open-access article distributed under the terms of the Creative Commons Attribution License (CC BY). The use, distribution or reproduction in other forums is permitted, provided the original author(s) and the copyright owner(s) are credited and that the original publication in this journal is cited, in accordance with accepted academic practice. No use, distribution or reproduction is permitted which does not comply with these terms. 